\title{
Cervical Consistency Index: A New Concept in Uterine Cervix Evaluation
}

\author{
${ }^{1,2}$ Miguel A Parra-Saavedra, ${ }^{1,4}$ Libardo A Gómez, ${ }^{1}$ Amanda Barrero, ${ }^{1}$ Guido Parra, ${ }^{1}$ Felipe Vergara, ${ }^{1}$ Is rael \\ Diaz-Yunez, ${ }^{1}$ Martha Gómez, ${ }^{3}$ Carlos Bermúdez, ${ }^{4} E$ ftichia V Kontopoulos, ${ }^{4}$ Rubén A Quintero \\ ${ }^{1}$ Maternal Fetal Medicine Unit, CEDIFETAL, Centro de Diagnóstico de Ultrasonido e Imágenes, CEDIUL, Barranquilla, Colombia \\ ${ }^{2}$ Northern General Clinic, Barranquilla, Colombia \\ ${ }^{3}$ Hospital Universitario de Caracas, Universidad Central de Venezuela, Caracas, Venezuela \\ ${ }^{4}$ Division of Maternal Fetal Medicine, Department of Obstetrics and Gynecology, University of Miami, USA
}

Correspondence: Miguel A Parra-Saavedra, Centro de Diagnóstico de Ultrasonido e Imágenes, CEDIUL, Calle 71 No. $41-46$ Barranquilla, Colombia, Phone: (5)3690011, (5)3153999003, Fax: (5)3459569, e-mail: miguelparra51@ hotmail.com

\section{ABSTRACT}

Objective: To search an ultrasonographic marker to measure cervix consistency throughout pregnancy quantitatively by transvaginal ultrasonography and compare these values with the current pattern - the cervicometry. In a randomly selected population of pregnant and nonpregnant women using a new cervical consistency index $(\mathrm{Cl})$ and compare these changes with the findings using cervicometry.

Methods: The cervical consistency index $(\mathrm{Cl})$ and cervicometry were measured using transvaginal ultrasonography in a reference population of randomly selected women who were mature enough for reproduction, and women in their first, second and third trimester of pregnancy. Patients with history of cervical conization, two or more dilations and miscarriages, Müllerian abnormalities and history of cervix incompetence were excluded from this study. Furthermore, patients with multiple pregnancies and cervical cerclage were not allowed to participate in this study.

Results: A total of 162 patients were evaluated for cervicometry and $\mathrm{CCl}$. Eighty of these women were not pregnant and the remaining 82 were pregnant. The database was analyzed using EPI-INFO version 6.0. Statistical values, such as the average, median and standard deviation between two groups, were analyzed. Statistically significant differences were found between nonpregnant and pregnant women in the first, second and third trimester regarding $\mathrm{CCl}$ with $\mathrm{p}<0.0001$. The cervix of pregnant women loses an average of $1.2 \%$ of consistency per week of pregnancy. Cervicometry did not show statistically significant difference among the groups $(p=0.4459)$.

Conclusion: $\mathrm{CCl}$ can quantitatively assess cervix consistency in pregnant and nonpregnant women, also found statistically significant differences between these groups and between the different trimesters of gestation, $\mathrm{CCl}$ also shows a remarkably circumscribed linear regression trend from early pregnancy. This ultrasound marker may serve in future for the early identification of patients at risk for preterm delivery. On cervicometry, there was no statistically significant differences between groups mentioned above.

Keywords: Cervical consistency index, Preterm labor, Cervical length, Cervix evaluation, Ultrasound.

\section{INTRODUCTION}

William Goodell, an A merican gynecologist (1829-94), was the first person who described the softening of the cervix as one of the changes associated to pregnancy, using the symbol of his name back in the 19th century. ${ }^{1}$

During the last century, Bishop also considered cervix consistency as a factor to determine if the cervix is in favorable conditions for the induction of delivery. ${ }^{2}$

However, to the best of our knowledge, this important cervical characteristic has not been evaluated quantitatively from the ultrasonography standpoint. ${ }^{3} \mathrm{~A} / \mathrm{l}$ the research conducted in the field of echography is based on cervicometry. ${ }^{4-8}$ The evaluation of cervical length by transvaginal ultrasound and changes in the internal cervical os are today the basis for identifying the risk of preterm delivery in the world, this is due to other screening strategies proposed as biochemical markers, maternal estriol in saliva, cervicovaginal biochemistry, and evaluation of amniotic fluid are expensive, invasive and are not commercially available everywhere and have low rates of detection. ${ }^{3}$ Thus, changes in cervical length measured by transvaginal scan have been inversely rel ated to risk of preterm delivery. ${ }^{9-12}$ However, there are controversies about the cutoff and the positive predictive value of the test, especially in low-risk populations.

Cervicometry changes exhibit a physiological pattern where progressive shortening after the 28th week is observed. Furthermore, nomograms have been published in order to predict preterm deliveries based on cervical length. ${ }^{9-11}$ However, the initial changes in the cervical ripening do not affect the length, but the consistency, because the cervix must first soften and then shortened, and research on the quantification of this variable has not been published before by any other research groups.

M odifications in cervicometry are few during the first 28 weeks of pregnancy with wide ranges of normal ity. Sensibility, specificity, positive predictive value and negative predictive value vary greatly according to the type of population. Cervicometry is not very helpful before the 14th week and after the 28th week, according to published research works. ${ }^{13-17}$ 
The aim of this study was to describe a new technique for measuring the consistency of the cervix by transvaginal ultrasonography (TVU) described as cervical consistency index (CCI) to determine if statistically significant differences occur between nonpregnant patients, pregnant women in the first, second and third trimesters, and compare these results with those obtained with cervicometria in the same population. ${ }^{18}$

\section{MATERIALS AND METHODS}

A total of 162 women were examined at M aternal Fetal Medicine Unit, CEDIFETAL, and at the Northern General Clinic in B arranquilla, Colombia, over a period of three months (from 1st A pril to 30th June, 2009) using transvaginal ultrasonography. These women were eval uated by cervicometry and $\mathrm{CCl}$ using a transversal cohort design.

The target population consisted of 80 nonpregnant women at fertile age (17-40 years old) and 82 pregnant women undergoing different trimesters of pregnancy, without history of conization, cervical suture, cervical incompetence or $M$ üllerian malformations. Patients with single pregnancy and no history of preterm delivery were included. The gestational age was determined based on the date of their last menstruation (DL M ) and confirmed by the first trimester ultrasound in all of the cases before the scan; patients participating in this study signed a written consent.

Cervix measurements were obtained by a specialist in prenatal ultrasound with over 4000 studies per year, during the last 10 years using the standard technique for cervicometry: Empty bladder, lithotomy position, visualization of cervix under minimum pressure in order to identify the endocervical canal, thus obtaining a cl ear image. Three measurements of the cervical length were conducted and the lowest of them was considered.

Endocervical funneling was not included in the calculation of cervicometry al though it was registered as an ultrasound scan finding.

M easurements were found using a $7 \mathrm{M} \mathrm{Hz}$ transvaginal probe (V oluson 730 Expert, GE Health care).

\section{$\mathrm{CCI}$ was evaluated by applying the following Technique: Technique for $\mathrm{CCI}$}

To determine the $\mathrm{CCl}$, examination was performed in five steps as follows:

First step: The cervical length is taken according to standard technique published previously by other authors. ${ }^{19}$ It is very important to avoid doing an excess pressure on the anterior lip (Fig. 1).

Second step: Once traced the cervical length, the screen is divided into two, leaving fixed on the left side the cervical length taken previously, and on the right side in real time, a pressure is made softly and progressively on the cervix until there is no visual observation of a greater shortening in the anteroposterior diameter (AP) or the cervix moves due to the pressure. To determine accurately the point of greatest shortening of the

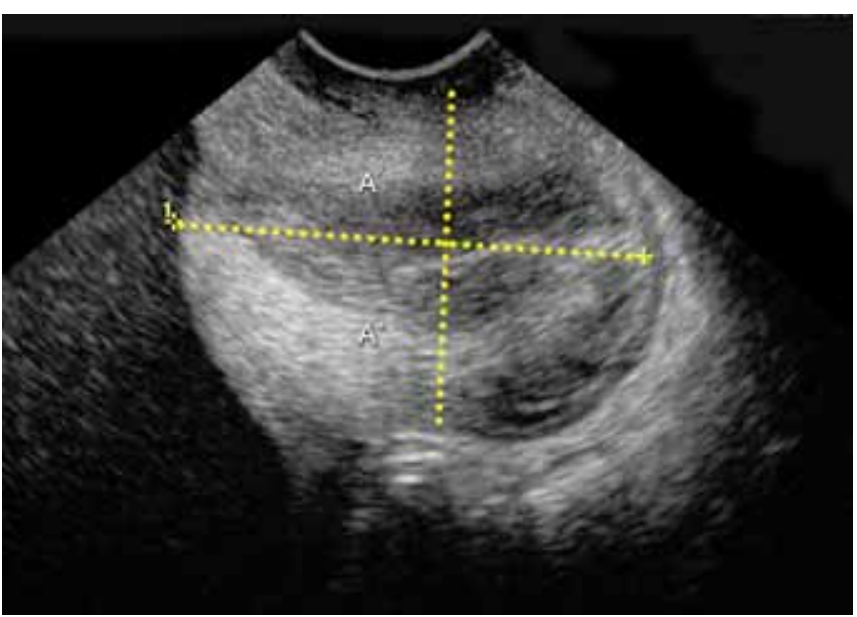

Fig. 1: The cervix must occupy at least $60 \%$ at both sides of the display

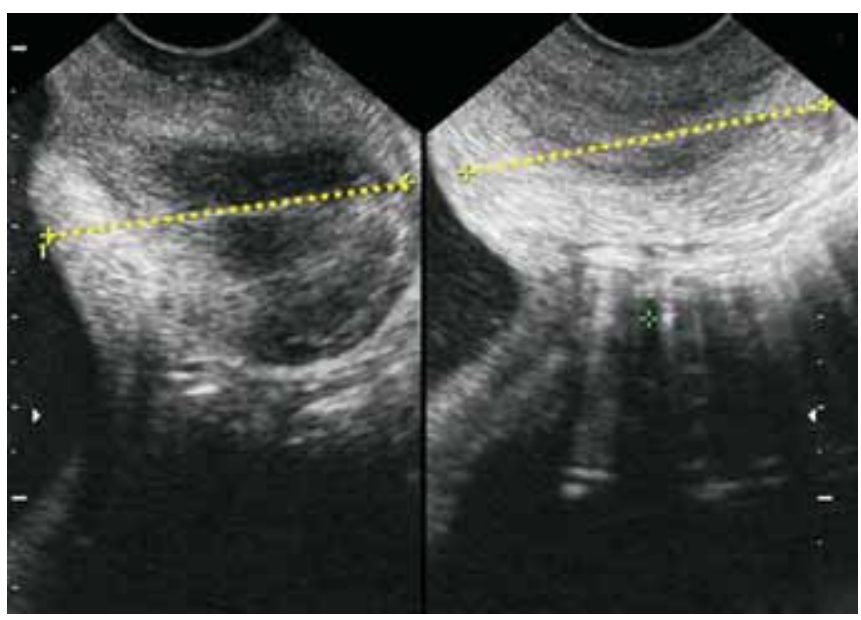

Fig. 2: A line is drawn in the right side, similar to the line used in cervicometry, joining $\mathrm{CIO}$ to $\mathrm{CEO}$. The same calculation is conducted in the left side by obtaining the lines $A$ and $B$

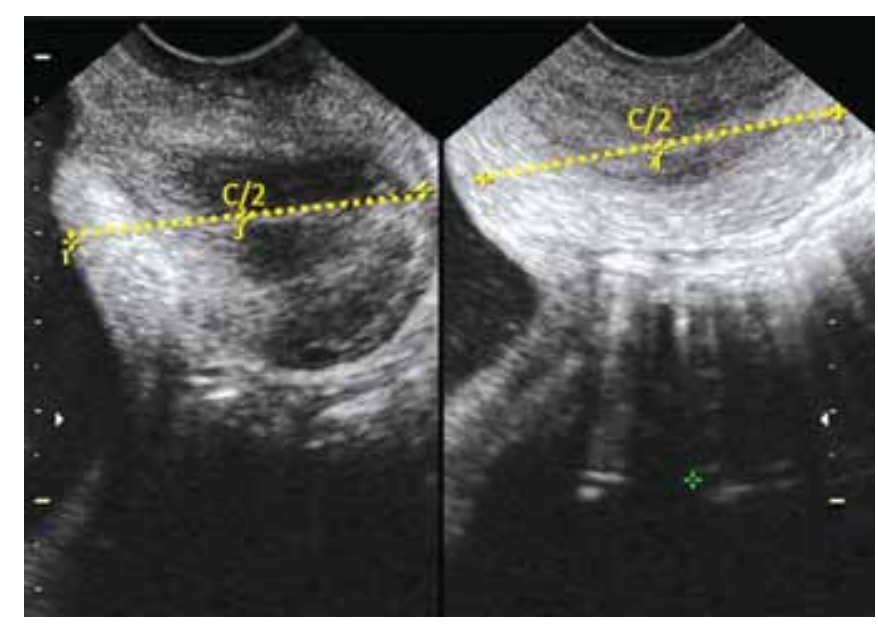

Fig. 3: The middle point of the lines $A$ and $B$ is found and the points $X$ and $Y$ are marked in both the right and the left side of the display respectively

cervix anteroposterior diameter, the cinel oop must be used in the equipment. A fter cervical length was measured on both sides of the screen, it is transported to the center line of the longitudinal axis of the cervix if this does not coincide with the longitudinal axis of the cervical canal as described in Figure 2. 
Cervical Consistency Index: A New Concept in Uterine Cervix Evaluation

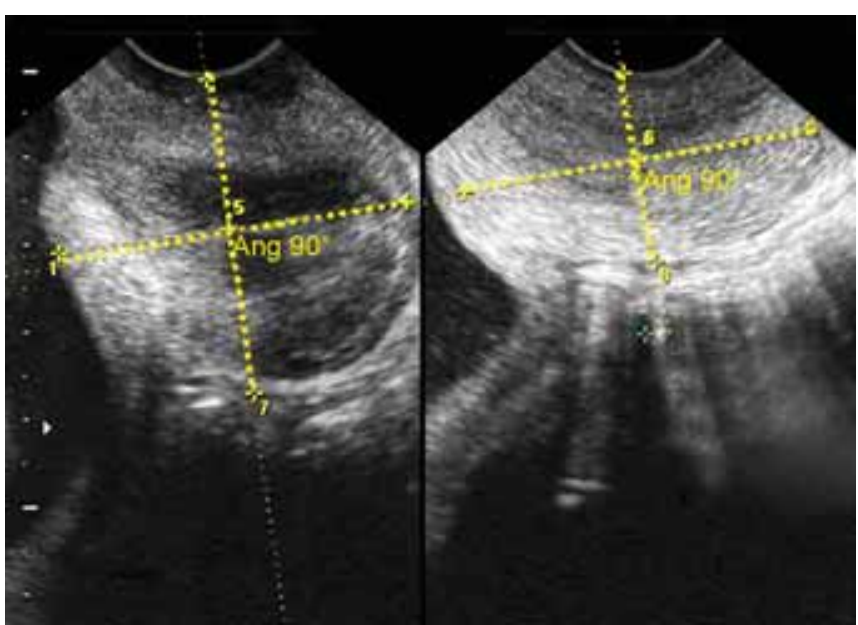

Fig. 4: A perpendicular line is drawn in these points $(X$ and $Y)$ on the right side to measure the distance between the most anterior point of the cervix anterior edge and the most posterior point of the cervix of the posterior edge, passing through the $X$ point. This length is called distance $C$. The same procedure is followed in the left side of the display thus obtaining the distance $D$

Third step: A half point of the cervical length transported to the center line of the longitudinal axis of the cervix is calculated (C/2) in both sides of the screen (Fig. 3).

Fourth step: In the half point of the cervical length transported to the center line of the longitudinal axis of the cervix $(\mathrm{C} / 2)$ is built a perpendicular with an angle of $90^{\circ}$ (to measure accurately this angle is used the option angle between 2 lines). On this perpendicular is measured the distance of the most anterior lip point placed anterior to the cervix, until the most posterior point of the lip, posterior of the cervix (A P). Then is made the same procedure on the right side of the screen, obtaining the distance A P' (Fig. 4).

Fifth step: Finally the A $P^{\prime}$ 'distance is divided by the A P distance and it is multiplied by 100 , obtaining this way the $\mathrm{CCl}$, by the equation: $\mathrm{CCl}=\mathrm{A} \mathrm{P}^{\prime} / \mathrm{AP} \times 100$.

In the previous example, AP $=46 \mathrm{~mm} ; A P^{\prime}=24 \mathrm{~mm}$. Then, $\mathrm{CCl}=24 \mathrm{~mm} / 46 \mathrm{~mm} \times 100$; finally, $\mathrm{CCl}=52 \%$ (see Fig. 4 ). ${ }^{18}$

The duration of the examinations was 5 to 9 minutes. All 2D ultrasound measurements were repeated two times, and the lowest of the two measurements was used for statistical analysis.

\section{RESULTS}

A population of 162 women was studied over a period of 3 months. This population was distributed as follows: Pregnant $80(49.4 \%)$, first trimester $24(14.8 \%)$, second trimester $15(9.3 \%)$ and third trimester $43(26.5 \%)$ (Table 1). The average age was 28.7 years no pregnancy group, 27 first trimester, 23.4 second trimester and 25.2 third trimester (Table 2). Statistically significant differences were found between nonpregnant and pregnant women in thefirst, second and thi rd trimester regarding CCI with $p<0.0001, r^{2}=0.64$. Thefoll owing mathematical model is based on those results (Table 3):

$$
\begin{aligned}
& \mathrm{CCl}=\mathrm{K}-[1.202 \times(\text { pregnancy age })] \\
& \mathrm{K}=89.53 \\
& \text { Pregnancy age: weeks }
\end{aligned}
$$

\begin{tabular}{|c|c|c|}
\hline \multicolumn{3}{|c|}{ Table 1: Distribution of patients } \\
\hline & $\mathrm{N}$ & $\%$ \\
\hline Not pregnant & 80 & 49.4 \\
\hline I trimester & 24 & 14.8 \\
\hline II trimester & 15 & 9.3 \\
\hline III trimester & 43 & 26.5 \\
\hline Total & 162 & 100 \\
\hline
\end{tabular}

Table 2: Age per group

\begin{tabular}{lcc}
\hline & $\begin{array}{c}\text { Median age } \\
\text { (years) }\end{array}$ & $\begin{array}{c}\text { Standard } \\
\text { deviation }\end{array}$ \\
\hline Not pregnant & 28.733 & 9.254 \\
I trimester & 27.095 & 5.195 \\
II trimester & 23.455 & 5.803 \\
III trimester & 25.256 & 5.185
\end{tabular}

$p=0.116$

Table 3: Average cervical consistency index per group

\begin{tabular}{llr}
\hline & CCl average (\%) & $\begin{array}{r}\text { Standard } \\
\text { deviation }\end{array}$ \\
\hline Not pregnant & 89.53 & 5.341 \\
I trimester & 75.083 & 14.331 \\
II trimester & 68.067 & 16.158 \\
III trimester & 49.581 & 10.872
\end{tabular}

$p<0.0001$

The value ' $\mathrm{K}$ ' corresponds to the average $\mathrm{CCl}$ value of nonpregnant women in our population.

The equation above indicates that the cervix of pregnant women loses an average of $1.2 \%$ of consistency per week of pregnancy and shows a clear inverse linear relationship with gestational age.

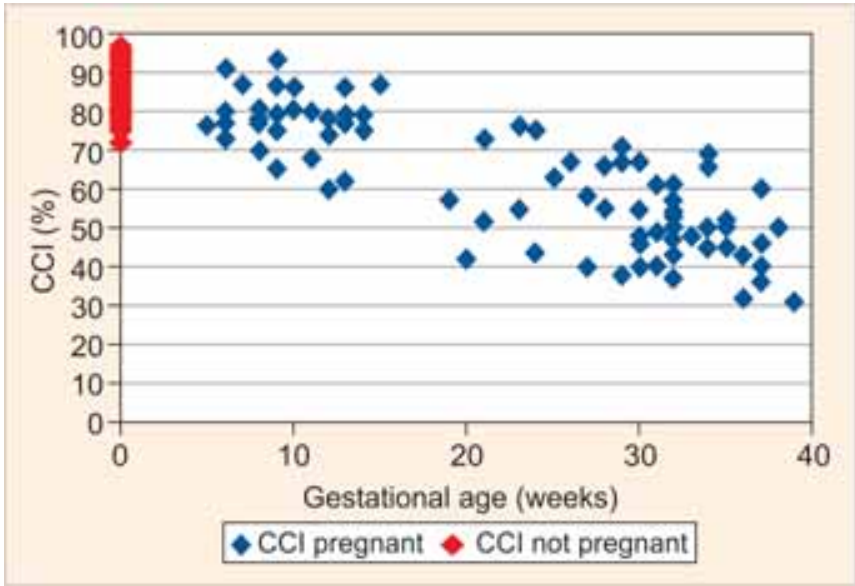

Graph 1: $\mathrm{CCl}(\%)$ not pregnant ( $\bullet)$, and pregnant $(\bullet)$ vs gestational age (weeks): The dispersion of values found in pregnant patients according to the gestational age. An inverse relation between $\mathrm{CCl}$ and pregnancy age is observed 


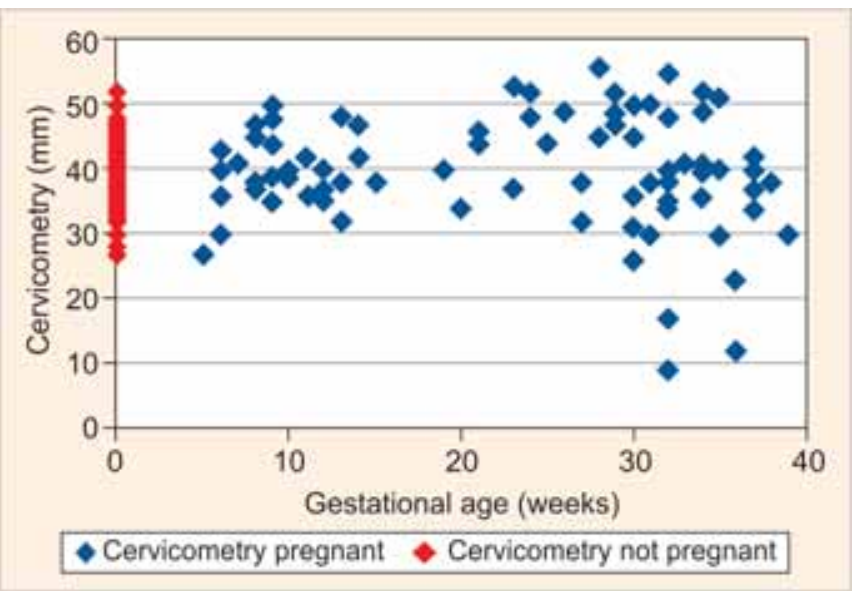

Graph 2: Cervicometry (mm) not pregnant $(\bullet)$, and pregnant ( $\bullet$ ) vs gestational age (weeks): The dispersion of values of cervicometry according to gestational age, where no statistical relation is observed between these two variables

\begin{tabular}{|lll|}
\hline \multicolumn{3}{|c|}{ Table 4: Cervicometry per group } \\
\hline & $\begin{array}{l}\text { Cervicometry } \\
\text { average }(\mathrm{mm})\end{array}$ & $\begin{array}{l}\text { Standard } \\
\text { deviation }\end{array}$ \\
\hline & 39.286 & 6.182 \\
\hline Not pregnant & 40.042 & 5.521 \\
I trimester & 42.133 & 6.069 \\
II trimester & 38.070 & 11.251 \\
III trimester & & \\
$\mathrm{p}=0.4459$ & & \\
\hline
\end{tabular}

Table 5: Criteria for the evaluation of effectiveness of a screening test

- Clinically important and prevalent condition

- Safe and well accepted

- Recognize disease in its asymptomatic phase

- A well-described technique, be reliable and reproducible

- The test has validity

- Associated with an intervention that prevents the outcome

Cervicometry did not show any statistically significant difference among the groups, $(p=0.4459)$ (Table 4). Funneling was present in six patients in the third trimester group.

\section{DISCUSSION}

The assessment of cervical consistency was registered only by pelvic examination and not considered of clinical value because of its low reproducibility; however, it has not been described ultrasound technique to measure the consistency of a quantitative and reproducible. ${ }^{20}$

To our knowledge, this is one of the first studies to evaluate the cervical consistency of pregnant and nonpregnant women with TVS.

It is important to assess the consistency of the cervix, because preterm delivery is possibly due to weakness of the cervix to maintain pregnancy and is directly related to the consistency of the cervix.
The cervicometry assumes homogeneity of consistency in relation to cervical length, all the cervix of $25 \mathrm{~mm}$ for instance, have the same mechanical strength to support the developing fetus, which according to our result is not true.

The cervix can lose up to $40 \%$ of its consistency with no evidence of changes in its length as shown by this work (dispersion Graphs 1 and 2). The advantage of measuring the consistency is given by their predictable behavior and linear regression, as well as in the sequence of events leading to the birth cervix must first soften and then shortened, so the changes in cervical consistency can determine a form of early detection of changes in cervical ripening even want the first trimester of pregnancy which would allow early identification of patients at risk of preterm delivery. The weaknesses of the technique are as follows: First, it requires a new skill to evaluate sonographic cervical consistency, this limitation can be overcomewith proper training and second, requires a equipment of high-definition ultrasound transducers over $6.5 \mathrm{M} \mathrm{Hz}$. It is also important to introduce the transducer with a good amount of gel into the vagina to reduce the difficulty in identifying the posterior wall of the vagina and not confused with the cervix.

Proper handling of the gain compensation curve is essential to overcome the difficulty described above of course coupled with the use of cinel oop as previously described by us, ${ }^{18}$ given that the forward and reverse image becomes easier to differentiate the vaginal fornix of cervical tissue. B efore looking at changes cervicometry, large variations in the consistency of the cervix could lead to channel shortening cervix (dispersion Graphs 1 and 2). In physiological terms, these changes end with the process of giving birth. Therefore, signs and channel cervicometry represent only the tip of an iceberg of a process initiated in the early stages of pregnancy, as evidenced by our records. These physiological changes in terms of consistency of the cervix and the length measured by the $\mathrm{CCl}$ and cervicometry are considered not only in the early diagnosis and monitoring patients at risk of preterm delivery, but also the evaluation of proposed treatments. ${ }^{21-23} \mathrm{CCl}$ will enable us to detect early stage patients at risk of preterm delivery. Further research involving a larger number of patients are needed to determine the role of $\mathrm{CCl}$ in the diagnosis of preterm labor and make decisions if this technique meets all requirements of a screening test, according to the criteria of $\mathrm{Grimes}^{24}$ (Table 5). Develop a method with which to assess the risk of preterm birth for each patient with cervical ultrasound including cervical length and $\mathrm{CCl}$ proposed that cervical length and the $\mathrm{CCl}$ are independent variables. This initial study opens the possibility to do research on a new way of assessing changes in the cervix that occur during pregnancy in a clinic. These changes can be very important in predicting preterm birth in preclinical stage, then considering this issue as part of perinatal medicine.

\section{REFERENCES}

1. Goodell William. Lessons in Gynecology. L ane M edical Library, Philadelphia, PA, DG B rinton, 115 south seventh street 1880. 
2. Bishop EH. Pelvic scoring for el ective induction. Obstet Gynecol 1964;24:266-68.

3. J oseph R W ax, A ngelina Cartin, M ichael G Pinette. Biophysical and biochemical screening for the risk of preterm labor. Clin Lab M ed 2010;30:693-707.

4. B urger $M$, W eber R ossler T, W illmann M . M easurement of the pregnant cervix by transvaginal sonography: A $n$ interobserver study and new standards to improve the interobserver variability. Ultrasound Obstet Gynecol 1997;9:188-93.

5. Hebbar S, K oirala S. R ole of midtrimester transvaginal cervical ultrasound in prediction of preterm delivery, JNMA. J Nepal Med Assoc 2006;45:357-61.

6. Rozenberg P, Gillet A, Ville Y. Transvaginal sonographic examination of the cervix in asymptomatic pregnant women: Review of the literature. Ultrasound Obstet Gynecol 2002;19:302-11.

7. Hoesli I, Tercanil S, Holzgreve W. Cervical length assessment by ultrasound as a predictor of preterm labour - is there a role for routine screening? BJ OG 2003;110:61-65.

8. Owen J. Evaluation of the cervix by ultrasound for the prediction of preterm births. Clin Perinatol 2003;30:735-55.

9. Salomon LJ, Diaz-Garcia C, B ernard JP, V ille Y. Reference range for cervical length throughout pregnancy: $N$ on-parametric L M S-based model applied to a large simple. Ultrasound O bstet Gynecol 2009;33:459-64.

10. Rovas L, Sladkevicius $P$, Strobel E, V al entine L. Reference data representative of normal findings at two-dimensional and threedimensional gray scale ultrasound examination of the cervix from 17 to 41 weeks gestation. U Itrasound Obstet Gynecol 2006;27:392-402.

11. V aladares S, Damiao R, FonsecaE, Garcia S, Lippi U . Reference ranges for cervical length by transvaginal scan in singleton pregnancies. J M atern Fetal Neonatal M ed 2010;23:379-82.

12. Kagan KO, To M, Tsoi E, Nicolaides K H. Preterm birth: The value of sonographic measurement of cervical length. BJOG 2006;113:52-56.

13. Iams JD, Paraskos J, landon M B, Teteris JN, J ohnson FF. Cervical sonography in preterm labor. Obstet Gynecol 1994;84:40-46.

14. Carvalho M HB, Bittar RE, B rizot M L, M aganha PPS, B orges Da Fonseca ESV , Zugaib M. Cervical length at 11 to 14 weeks gestation evaluated by transvaginal sonography, and gestational age at delivery. U Itrasound O bstet Gynecol 2003;21:135-39.

15. Conoscenti G, M eir J , D' ottavio G, Rustico M A, Pinzano R, et al. D oes cervical length at 13-15 weeks gestation predict preterm delivery in an unselected population? U Itrasound Obstet Gynecol 2003;21:128-34.

16. Mirza FG, House M, Craigo SD, U rato AC. The patient with asymptomatic shortened cervix at 23 to 28 weeks: Is delivery inminent? A m J Perinatol 2009 (Epub ahead of print) PM D: 1968, 5419.

17. J enkins SM , K urtzman JT, O sann K. Dynamic cervical change: Is real-time sonographic cervical shortening predictive of preterm delivery in patients with symtomps of preterm labor? Ultrasound Obstet Gynecol 2006;27:373-76.

18. M Parra-Saavedra, L Gómez, A B arrero, G Parra, F V ergara, E Navarro. Prediction of preterm birth using the cervical consistency index. Ultrasound Obstet Gynecol 2011;38:44-51.

19. VCF Heath, TR Southall, AP Souka, A Novakov, KH Nicolaides. Cervical length at 23 weeks of gestation: Relation to demographic characteristics and previous obstetric history, ultrasound Obstet Gynecol 1998;12:304-11.

20. Rachel L Copper, Robert L Goldenberg, M ary B Dubard, John C Hauth, Gary R Cuttter. Cervical examination and tocodynamometry at 28 weeks' gestation: Prediction of spontaneous preterm birth. AJOG 1995;172:666-71.

21. Fonseca EB, Celik E, Parra M, Singh M, Nicolaides KH. Progesterone and the risk of preterm birth among women with a short cervix. N Engl J M ed 2007;57:462-69.

22. EA Defranco, JM O'brien, CD Adair, DF Lewis, DR Hall, Fusey $\mathrm{S}$, et al. Principio del formulario. $\mathrm{V}$ aginal progesterone is associated with a decrease in risk for early preterm birth and improved neonatal outcome in women with a short cervix: A secondary analysis from a randomized, double-blind, placebocontrolled trial. Ultrasound Obstet Gynecol 2007;30:697-705.

23. Hassan SS, Romero R, V idyadhari D, Fusey S, Baxter JK, $K$ handelwal $M$, et al. $V$ aginal progesterone reduces the rate of preterm birth in women with a sonographic short cervix: A multicenter, randomized, double-blind, placebo-controlled trial. Ultrasound Obstet Gynecol 2011;38:18-23.

24. Grimes-Dennis J, B erghella V. Cervical length and prediction of preterm delivery. Curr O pin Obstet Gynecol 2007;19:191-95. 